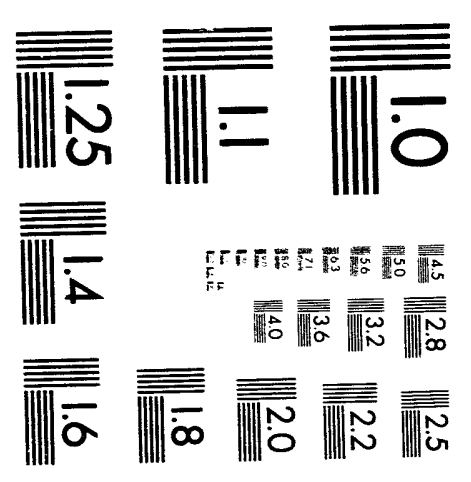



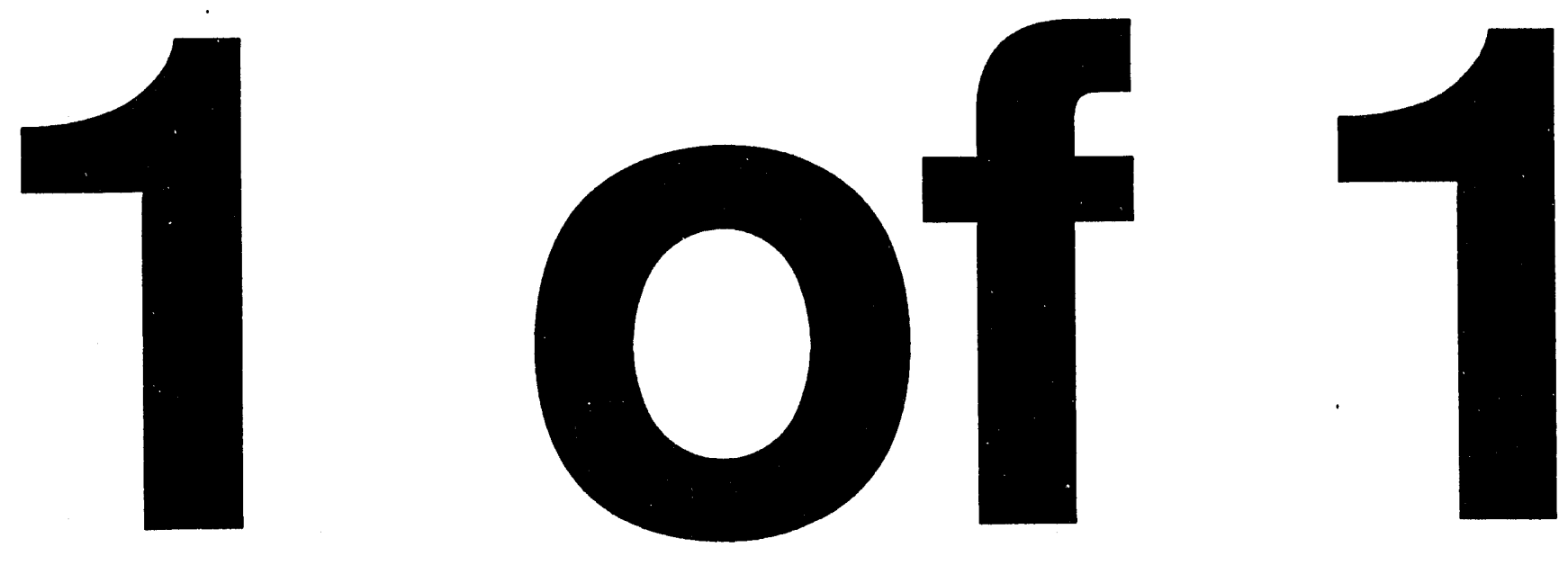
Dosimetry at the Los Alamos Critical

Experiments Facility: Past, Present, and Future

Richard E. Malenfant 


\section{TABLE OF CONTENTS}

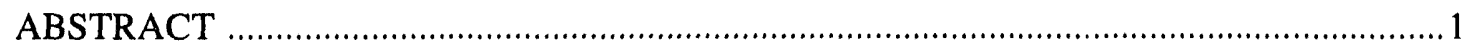

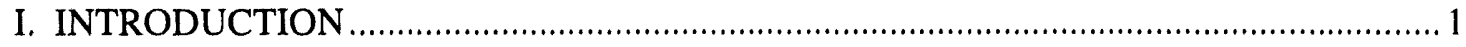

II. FACILITY DESCRIPTION

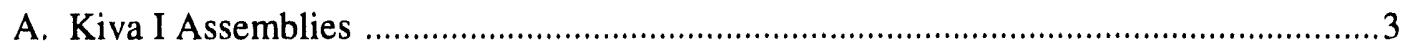

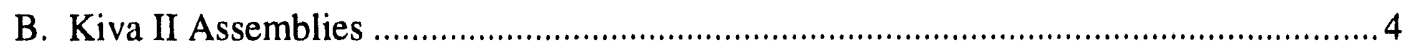

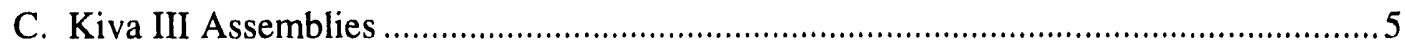

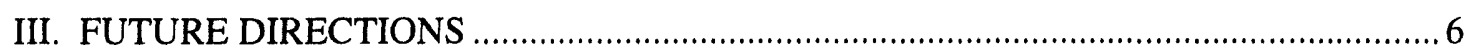

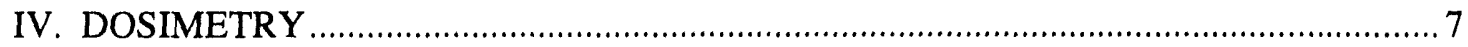

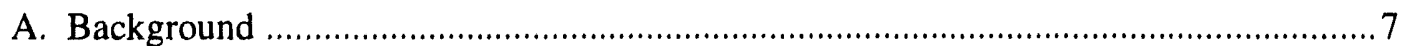

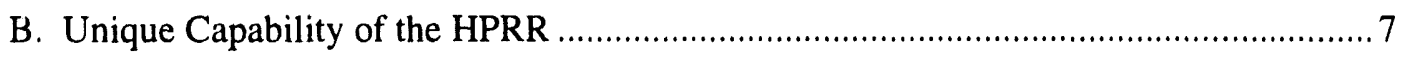

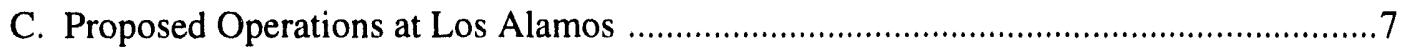

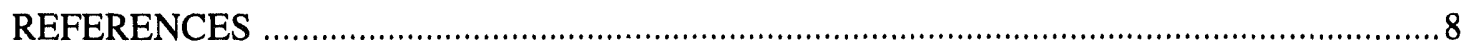




\title{
DOSIMETRY AT THE LOS ALAMOS CRITICAL EXPERIMENTS FACILITY: PAST, PRESENT, AND FUTURE
}

\author{
by
}

\author{
Richard E. Malenfant
}

\begin{abstract}
Although the primary reason for the existence of the Los Alamos Critical Experiments Facility is to provide basic data on the physics of systems of fissile material, the physical arrangements and ability to provide sources of radiation have led to applications for all types of radiation dosimetry. In the broad definition of radiation phenomena, the facility has provided sources to evaluate biological effects, radiation shielding and transport, and measurements of basic parameters such as the evaluation of delayed neutron parameters. Within the last 15 years, many of the radiation measurements have been directed to calibration and intercomparison of dosimetry related to nuclear criticality safety. Future plans include (1) the new applications of Godiva IV, a bare-metal pulse assembly, for dosimetry (including an evaluation of neutron and gamma-ray room return); (2) a proposal to relocate the Health Physics Research Reactor from the Oak Ridge National Laboratory to Los Alamos, which will provide the opportunity to continue the application of a primary benchmark source to radiation dosimetry; and (3) a proposal to employ SHEBA, a low-enrichment solution assembly, for accident dosimetry and evaluation.
\end{abstract}

\section{INTRODUCTION}

The first critical experiments at the Los Alamos Critical Experiments Facility (LACEF) ${ }^{1,2}$ were conducted in 1945. The first documented application of the facility to dosimetry followed the fatal accident of 21 May 1946. Although the first fatality resulted from an accident on 21 August 1945, no serious attempt could be made to characterize the dose (which was estimated at 800 rep") because only one individual was involved, and he was working alone. The 21 May 1946 accident involved eight participants. Following the accident, Louis Slotin (the only fatality) requested that all participants be surveyed in an attempt to establish at least the relative exposures. This was done in a crude way by evaluating the activation of silver coins, gold and silver fillings in the teeth, and blood sodium activation. Stratton ${ }^{3.4}$ reports estimated doses of $900,185,116,93,41,26,18$, and 18 rep.

The attempt to understand and evaluate biological radiation effects is extremely difficult and very sensitive. The difficulty is compounded by several facts: radiation is everywhere in nature; there is no

\footnotetext{
* Units will be reported as originally documented.
} 
one-to-one correlation between exposure and the production of an observable effect; and calibrated dosimeters were not employed for the exposed populations. The determination of the effect, and subsequent establishment of safe limits, must be derived from statistical evaluations of exposed and identical control populations In many instances, the observations must be made over several years, if not decades.

The nature of the radiation itself also poses serious problems. It is not sufficient to characterize a single source. Neutrons and gamma rays differ in their interactions with matter, and the former are converted to the latter by capture. When alpha, beta, and low-energy photons are included, self-shielding in the receptor becomes significant (the depth-dose problem).

The following three examples may illustrate some of the subtle difficulties:

Example 1: Average-energy problem. The average energy of gamma rays resulting from fission and fission products in equilibrium is about $1 \mathrm{MeV}$; however, the average energy of gamma-rays resulting from neutron capture is about $2 \mathrm{MeV}$. Hydrogen has a single-capture gamma ray at $2.23 \mathrm{MeV}$, and hydrogen dominates the source of capture gamma rays for water and many concretes. In nitrogen, about $40 \%$ of the captures result in a direct transition to the ground state at $10.8 \mathrm{MeV} .{ }^{5}$ When boron is used to suppress neutron scatter, it results in a $0.51-\mathrm{MeV}$ gamma ray from the decay of an excited state of ${ }^{7} \mathrm{Li}$, resulting from capture in "'B. The apparent mean-free path in air of gamma rays from fission is about $200 \mathrm{~m}(600 \mathrm{ft})$, whereas the apparent mean-free path of gamma rays some distance from an operating reactor is about $400 \mathrm{~m}(1300 \mathrm{ft}){ }^{6}$

Example 2: Fission basis of power problem. According to Glasstone, ${ }^{7}$ fissions at the rate of $3.1 \times 10^{11}$ per second produce $1 \mathrm{~W}$. Unfortunately, this is now considered to be a constant of nature. The derivation of the "constant" considers a large system (very small fractional leakage) with all fission products at equilibrium. For a small system operating for a short time, such as a metal pulse reactor, it requires about $3.6 \times 10^{11}$ fissions per second to produce $1 \mathrm{~W}$, a difference of $16 \%$.

Example 3: Detector response. There are two major problems with detector response. The first deals with the depth-dose effect. We are all familiar with the fact that skin dose, or free air dose, is not the same as organ dose because of the shielding effect of intervening material; however, a related problem occurs for detectors. Consider the use of a Geiger counter to evaluate the dose from a ${ }^{61} \mathrm{Co}$ source. The counter has been carefully calibrated to read dose in some convenient units - for example, tissue rads. Of course, the actual method of detection is through the interaction of gamma rays with the walls of the chamber to produce electrons that then produce a pulse of energy. Now, consider the use of this detector to evaluate a dose resulting from air-scattering of gamma rays from ${ }^{61} \mathrm{Co}$ around a shield. When the $1.25-\mathrm{MeV}$ averageenergy gamma rays from ${ }^{61} \mathrm{Co}$ scatter through $180 \mathrm{deg}$, the resulting gamma rays have an energy of $0.208 \mathrm{MeV} .{ }^{8}$ Indeed, any scattering of $>65 \mathrm{deg}$ results in a gamma ray of $<0.5 \mathrm{MeV}$. A Geiger counter calibrated (to indicate dose) to be precisely correct at $1.25 \mathrm{MeV}$ will indicate a factor of 5-7 high when exposed to $0.2-\mathrm{MeV}$ photons.

LACEF has been used to evaluate these phenomena for over 40 years. We now propose to expand the facility to provide the capability for radiation accident dosimetry and simulation. The results should complement the work being done at Valduc with SILENE.

\section{FACILITY DESCRIPTION}

Since the LACEF has been described in the past, 1.2 it will only be summarized here: 
LACEF consists of three remote-control laboratories, known as "kivas," which are located about $400 \mathrm{~m}$ from the main laboratory building that houses a separate control room for each kiva. The entire site that contains the LACEF also supports activities in arms control, waste assay, and nuclear emergency response, with a total of $\sim 70$ personnel at the site. Accordingly, in addition to security fences, each kiva is further surrounded by a safety fence to keep personnel at a safe distance during remote operations. Personnel enter the kivas through an eiaborate security and safety procedure with a strictly imposed "twoperson" rule. Several general-purpose assembly machines occupy each kiva. In some instances, assembly machines are constructed specifically for the purpose of conducting a particular experiment. At the present time, the use of a source-jerk technique to evaluate the degree of subcriticality of storage arrays is being evaluated in Kiva III. In addition to the machines, the site also houses storage facilities for the material needed to construct fissile arrays.

The facility represents three basic capabilities. The first is the physical arrangement that allows experiments to be built quickly and easily on any of the general-purpose machines. As described below, we operate one, general horizontal assembly machine; four, general vertical machines; two, fixedgeometry benchmark assemblies; two, metal fast-burst (or pulse) assemblies; and one solution assembly. It is quite feasible to operate all three kivas simultaneously and to have several experiments mounted on the different machines ready to operate.

Personnel are the second basic capability. Senior experimenters are assigned the responsibility for the design, construction, operation, and analysis of various assemblies. There are no dedicated operators of the assemblies; rather, all functions are conducted by or are under the direct supervision of the scientific staff.

The third capability is in the inventory of material. The site serves as a storage facility for various forms of material useful in a program of experiments. At the present time this includes highly enriched uranium (HEU) metal as unclad foils, disks, and plates, in addition to fabricated components for the benchmark machines. Canned alpha-phase metallic plutonium and clad stabilized delta-phase plutonium in several shapes are also available. Compounds include HEU as the nitrate, low-enriched uranium (LEU) as the fluoride, and canned plutonium oxide and several enrichments of canned uranium oxide, in addition to some canned mixed oxide. Measurements have also been made on small samples of fissionable and non-fissionable actinides. Non-fissile material that is readily available includes various forms of lucite, polyethylene, graphite, aluminum, steel, and beryllium.

\section{A. Kiva I Assemblies}

The five machines detailed below are presently situated in the area of Kiva I, which is our oldest kiva, having the first remote operations in 1947. In the mid-80s, Kiva I was modified to employ a digital control system that provides full computer control of the assemblies.

SHEBA: This assembly is housed in a simple aluminum building outside of Kiva I. The present version of SHEBA achieved first critical on 6 September 1980, just 4.5 months after funding approval for the program was received. SHEBA is a bare assembly fueled with a solution of $\sim 5 \%$ enriched uranyl fluoride. The solution is transferred to the 56-cm-diam stainless-steel reaction tank by differential pressure. A completely clean geometry is provided because reactivity control is effected by varying solution level. A safety rod may be inserted in a central thimble to provide fast shutdown; although a fast-acting, pneumatically controlled dump valve has also proven very effective. The critical solution height is $36.5 \mathrm{~cm}$ at $25^{\circ} \mathrm{C}$, which corresponds to $85.5 \mathrm{~L}$ of solution in the cavity. SHEBA has been most useful for evaluating the response of accidental criticality alarm systems and for demonstrating the properties of slow excursions in a solution assembly. Over the last 2 years, SHEBA has been modified to improve the safety and reliability of operation and eventually to accommodate more energetic excursions for 
comparison with the French CRAC data from SILENE, the highly enriched nitrate assembly. At this time (Spring 1993), SHEBA is ready to function and is being operated with water to simulate the fuel to verify functioning and to train the experimenters in the operation. The U.S. Department of Energy (DOE) has required an Operational Readiness Review, which is being conducted.

Honeycomb: A universal horizontal split-table machine, Honeycomb contains a 1.83-m cube matrix of 76-mm square aluminum tubes. It is designed as a flexible system to accommodate initial mock-up studies for basic critical parameter investigations. Graphite, beryllium, canned beryllium oxide, iron, aluminum, niobium, molybdenum, tungsten, zirconium, and zirconium hydride are available as blocks, bars, plates, and foils to support most programs of interest. The fuel inventory consists of U(93) as foils. Additional $U(93)$ and $U(20)$ are available as oxide and carbide in forms compatible with the Honeycomb matrix. Control and safety elements may be mocked up on either the fixed or movable half of the machine to manipulate sections of core, reflector, or absorber elements. At the present time, a graduate student is designing an experiment to place interacting containers of $\mathrm{U}(93)$ as the nitrate on the Honeycomb machine. This machine was used for early experiments with uranium-graphite assemblies and, more recently, as a sintered uranium oxide, beryllium-reflected mockup of a reactor for space nuclear power.

Mars: This heavy-duty vertical assembly stand contains a hydraulic cylinder recessed in the floor to provide primary assembly motion. The Mars machine is presently stacked with a graphite matrix (no fuel) to verify the function of all controls. We propose to use the Mars machine to perform the critical experiments for the Advanced Neutron Source Reactor being designed by Oak Ridge National Laboratory (ORNL).

Venus: Another heavy-duty vertical assembly stand similar to Mars is Venus. Although presently unloaded, it was last used to measure the interaction between two cylinders of $U(93)$ as the nitrate in a storage array.

Planet: A light-duty vertical assembly stand, Planet is presently configured (although unloaded) to measure the interaction of an array of slab tanks containing $U(93)$ as the nitrate. This array of material was recently used to evaluate different techniques for evaluating $\mathrm{k}_{\text {eff }}$ for a subcritical system. We are presently preparing an Experiment Plan to operate an experiment to demonstrate criticality safety on the Planet machine.

\section{B. Kiva II Assemblies}

Kiva II houses three assembly machines. Two of these are fixed-geometry, and one is a generalpurpose machine.

Flattop: This is a thick, natural-uranium metal reflector (with a $0.48-\mathrm{m}$ o.d. and a gross weight of 1000 $\mathrm{kg}$ ) surrounding spherical cores of uranium $\left(93.2 \%{ }^{235} \mathrm{U}\right.$ or $\left.98.1 \%{ }^{233} \mathrm{U}\right)$ and plutonium $\left(94.9 \%{ }^{239} \mathrm{Pu}\right)$. Different adapter shells of natural uranium allow adjustment of the central reflector cavity for close fit to the various cores. Two quarter-sections of the reflector are movable and provide prompt and effective shutdown. The fixed half of the reflector contains three rods of natural uranium metal that provide fine control by changing leakage. Because there are no large voids - indeed, there are very small voids - the system is very docile. For several years, we have allowed students in our nuclear-criticality-safety training classes to operate Flattop under close supervision. The machine provides a graphic demonstration of the ease and safety of operating a 40-year-old machine with a plutonium metal core. Recently, Flattop with the uranium core has been employed to demonstrate the results of slow excursions for comparison with the results from SILENE and SHEBA. 
Big Ten: A cylindrical assembly, Big Ten comprises a ${ }^{23.5} \mathrm{U}(10 \%)$ core surrounded by a depleted-uranium metal reflector. Overall, the $10000-\mathrm{kg}$ machine is $0.84 \mathrm{~m}$ in diameter and $0.96 \mathrm{~m}$ long. The reflector has 0.15 -m-thick walls and 0.21 -m-thick ends. Major disassembly of the horizontal machine is provided by a removable reflector section $0.39 \mathrm{~m}$ long; the stationary section containing the core is $0.57 \mathrm{~m}$ long. Twelve movable 88.9-mm-diam rods of depleted uranium are located in the peripheral reflector. Six rods in the movable section and five rods in the stationary section operate in the "in/out" mode, with no intermediate positions available, and act as safety rods. The sixth rod in the stationary section and a 38-mm-diam ${ }^{23.5} \mathrm{U}(10 \%)$ rod along the axis act as control rods, which are continuously adjustable, and their positions are read out accurately in the control room. As with Flattop, Big Ten is a benchmarked machine. Reactivity measurements in the different spectra in the two machines provide two integral measurements to validate computer codes. Again, as with Flattop, Big Ten is a very docile machine. Even hydrogen in the small sample space inside the core has no net effect on reactivity, because the positive effect of downscattering and the negative effect of absorption cancel out each other in the spectrum in the core of Big Ten. Although the mass of the machine allows operating it near $10^{14}$ fissions $/ \mathrm{s}(4000 \mathrm{kw})$, the control rods must be adjusted continuously to keep up with the loss of reactivity that is due to thermal effects; and the control margin is such that the machine eventually shuts itself down when we run out of reactivity to add.

Comet: A light-duty vertical assembly stand with provision for additional manipulation of components from the top of the machine, "Comet" is also the oldest survivor of the general-purpose light-duty vertical assembly machines on the site. It derives its name from Jano Haley, a member of the staff 40 years ago who built Haley's Comet! This machine is used at present for the nuclear-criticality-safety training classes, where instructors hand-stack ${ }^{235} \mathrm{U}(93 \%)$ foils between lucite plates until a multiplication of 10 is reached (our limit for hand-stacking); at which point, the stack is split between a platen on the COMET stand and a lift. Uranium foil/lucite plate combinations are then added, alternating between the stack on the lift and the stack on the platen (with remote assembly between additions) until a multiplication of 100 $\left(\mathrm{k}_{\text {eft }}\right.$ about 0.99$)$ is reached. At this point, the experiment is complete because no provision is made for control elements. Of course, when the stack is near the end point, reciprocal multiplication is observed during closure to comply with accepted and approved procedures for such operations. Comet has been used for many other measurements: The replica of Little Boy was run on the Comet machine. We have also used it to measure the parameters . . plutonium with different isotopic compositions and various compounds of uranium, such as the hydride. The machine has also been used for safety studies to evaluate the effects of accidents involving flooding systems with water. It is ironic that the original allegations regarding safety of operations were made about a safe operation on a machine that has been so heavily used in studies related to nuclear criticality safety.

\section{Kiva III Assemblies}

Kiva III houses our two metal burst assemblies. When built in 1960, the kiva had to be located closer to the control rooms than the other two kivas. As such, Kiva III is the only kiva that relies on concrete walls for shielding, although the primary dose on site results from leakage through the roof, with subsequent air scatter and capture.

Godiva IV: This is the latest in the line of unreflected uranium critical assemblies. The original spherical Godiva I (Lady Godiva) established an accurate value for the critical mass of a ${ }^{235} \mathrm{U}$ unreflected sphere. That system demonstrated the self-quenching features of metal critical assemblies. Maximum bursts of $2 \times 10^{16}$ fissions with a half-width of $35 \mathrm{~ms}$ were produced with peak powers of $10000 \mathrm{MW}$. Subsequent work with Godiva IV produced bursts in excess of $4 \times 10^{16}$ fissions, with half-widths of $50 \mathrm{~ms}$ and peak powers of one-hundred-thousand megawatts. Total dose at $3 \mathrm{~m}$ from Godiva in a $4 \times 10^{16}$ fission burst is about 500 rem. In the 1960s, a Godiva-like reactor was operated at the Nevada Test Site on top of a 470-m-high tower to provide data on the exposures to neutrons and gamma rays at Hiroshima and 
Nagasaki. Until recently, that reactor (actually a Godiva II) has been operated at ORNL as the Health Physics Research Reactor (HPRR) to evaluate dosimetry.

Skua: Our newest fast-burst metal reactor, Skua consists of $175 \mathrm{~kg}$ of ${ }^{235} \mathrm{U}(93 \%)$ with copper reflectors. An internal cavity with a flux trap in the cylindrical reactor accommodates material for exposures. Bursts of $2 \times 10^{17}$ fissions are within the capability of Skua, although the larger size indicates a half-width of about $100 \mathrm{~ms}$.

\section{FUTURE DIRECTIONS}

The classical reasons to support a facility to conduct critical experiments no longer exist because nearly every measurement that can be made, has been made. However, the Defense Nuclear Facilities Safety Board (DNFSB) recently recognized the continued need for critical experiments. ${ }^{9}$ Calculational techniques have improved to the point that the statement that everything can be calculated is almost true. However, we have defined six areas of work that remain for the LACEF.

1. Training. For nearly 20 years, personnel from DOE facilities have participated in a hands-on program of training and familiarization at the LACEF. During the time that operations were suspended, the facilities to provide that training have been modernized and improved. The control room for Kiva II (where the experiments are conducted) has been modified to better serve as a classroom. The first experiments to be conducted following resumption of operations are aimed at improving the training. At the present time, we anticipate that 10-12 classes of 20-25 students can be accommodated every year.

2. Expanded Training. Even though there is a continuing need for specialists in nuclear criticality safety, there is no program in the United States to train replacements for the veterans who are nearing retirement age. We propose to expand the training function of the LACEF and work in conjunction with the universities to provide training for students under the supervision of university professors. In addition, we propose to invite students working toward certification as health physicists to serve a residency at the LACEF to become familiar with the problems of nuclear criticality safety. At the present time, we are working with the DOE to see if this service can be provided at no cost to the participants.

3. Process Validation. Even with the power of modern computers and well-validated computational techniques, there is a continuing need to explore the safety of chemical processes particularly those off-normal processes that have been involved in most accidents of the past. This validation cannot be done by computation alone. This function serves much the same purpose as an insurance policy. The accidents at Chernobyl and Three Mile Island demonstrate the vulnerability of the industry. Off-normal processes must be validated to avoid the consequences of another accident.

4. Criticality Alarm System Validation. Experience has demonstrated that designing and implementing an accidental criticality alarm system without validating it by exposure to an actual system operating at critical can lead to a false sense of security. For more detail, please refer to Ref. 2, which describes the alarm-system response to a slow criticality.

5. Dosimetry. Reference has already been made to the history and use of metal burst reactors to standardize and validate dosimetry; however, the HPRR at ORNL is currently not available. The open spaces at the LACEF and availability of a HPRR-like assembly would allow this service to continue at Los Alamos.

6. Basic Nuclear Research. Experiments that explore the unknowns which remain in the physics of critical systems is a continuing need. There are several calculations with strange results; nuclear cross 
sections are always suspect; large interacting arrays of dissimilar elements still present a challenge to the most sophisticated Monte Carlo techniques; and new applications, such as the accelerator transmutation of waste, pose questions that can be readily answered by a well-designed integral experiment. In addition, the staff at the LACEF needs to be challenged to expand their experimental capability. It is difficult to derive satisfaction from the oft-repeated experiment for a nuclear criticality safety training class - we know the answer. Perhaps, it is just that familiarity that contributed to the perception of the participant in the class that resulted in the suspension of operations for 18 months.

\section{DOSIMETRY}

LACEF proposes the development of a User Facility that incorporates the HPRR, Godiva IV, and Sheba to provide well-characterized, mixed (neutron and gamma ray) radiation sources for accident simulation and the calibration and intercomparison of radiation dosimetry. This User Facility would be maintained by the DOE as part of the base capability documented by the DNFSB and would be available to users at the marginal cost of operation. We specifically propose to replace the facility at ORNL that used the HPRR for this purpose until it had to be shut down because of budgetary considerations.

\section{A. Background}

Essentially all radiation-exposure standards for humans are related to the observations resulting from Hiroshima and Nagasaki. Since those exposures were not instrumented, a 45-year program has been conducted to characterize them. Part of that characterization was conducted in the 1960s when HPRR, a Godiva-like, bare, enriched-uranium, fast-burst reactor, was operated on a tower at the Nevada Test Site to evaluate neutron and gamma-ray exposures on the ground. Although neither the spectra, nor the neutron-to-gamma ratio, nor the leakage per fission matched either of the sources in Japan, the data resulting from that study were the best available. Upon retirement, that fast-burst reactor became the basis of the DOSAR facility at ORNL, where it served as a primary source for calibration and intercomparison until 1986.

\section{B. Unique Capability of the HPRR}

The HPRR is not the only fast-burst reactor in existence. Godiva-like bare-metal assemblies still exist at White Sands Missile Range, Aberdeen Proving Ground, Sandia National Laboratories (Albuquerque), and Los Alamos National Laboratory. However, none of these facilities provide the pedigree of the HPRR, which includes a cylindrical reactor of HEU (with $10 \%$ molybdenum) that can be operated in a good geometry situation, employing the well-characterized shields used at ORNL. Fastburst reactors also exist in Russia and China, although none have the unique characteristics of the HPRR facility.

\section{Proposed Operations at Los Alamos}

HPRR: We propose to place the HPRR in Kiva II so that it can be moved outside into a thin-metal weather shed. The Kiva II area offers a free line of nearly $400 \mathrm{~m}$ to facilitate radiation transport measurements, and we propose to relocate the shields from Oak Ridge to Los Alamos to maintain the traceable standards of dosimetry.

Godiva IV: We will continue to operate Godiva IV in steady-state and burst mode in Kiva III. In addition, we propose to provide the capability to operate the assembly outside of Kiva III in a thin-metal weather shed to fully evaluate room return and room capture. Radiation measurements on Godiva IV have been made out to distances of nearly $5 \mathrm{~km}$, albeit with some difficulty. 
SHEBA: As in the past, we propose to operate SHEBA in the thin-metal weather shed. This provides a capability to evaluate radiation transport in a good geometry situation to free line distances of $400 \mathrm{~m}$. In addition, we propose to operate SHEBA in a shielded hole in the ground in the super-prompt critical mode for comparison with the French CRAC experiments.

Other sources: We also propose to evaluate the feasibility of operating the Little Boy Assernbly ${ }^{10}$ to evaluate neutron and gamma-ray leakage, air transport, and the neutron quality factor. Other assembly machines are also being evaluated for this purpose.

\section{REFERENCES}

1. R. E. Malenfant, "Los Alamos Critical Experiments Facility," Los Alamos National Laboratory report LA-8762-MS (June 1981).

2. Richard E. Malenfant, "Los Alamos Critical Experiments Facility," Paper VII:2, Proceedings of the ICNC'91 International Conference On Nuclear Criticality Safety, 9-13 September 1991, Oxford, UK, Los Alamos National Laboratory document LA-UR 91-216).

3. William R. Stratton, "A Review Of Criticality Accidents," Los Alamos Scientific Laboratory report LA-3611, (January 1967).

4. William R. Stratton (revised by DAVID R. SMITH), "A Review of Criticality Accidents," DOE90015896 (March 1989).

5. L. V. Groshev, V.N. Lutsenko, A.M. Demidov, and V.I. Pelekhov, "Atlas of Gamma-Ray Spectra From Radiative Capture of Thermal Neutrons," (Pergamon Press, 1959).

6. Richard E. Malenfant and Glen A. Graves, "Ground Test Radiation Experience at the Kiwi B-4 Tests," AIAA Paper No. 65-593, AIAA Propulsion Joint Specialist Conference, Colorado Springs, Colorado, June 14-18, 1965.

7. Samuel Glasstone, "Principles of Nuclear Reactor Engineering," (D. Van Nostrand Company, Inc., 1955), p. 24.

8. B. T. Price, C. C. Horton, and K. T. Spinney, "Radiation Shielding," in International Series of Monographs on Nuclear Energy (Pergaman Press, 1957) p. 29.

9. The Federal Register, Vol. 58, No. 59, Tuesday, March 30, 1993, p. 16654.

10. SPECIAL SESSION, "Measurements on a True Replica of Little Boy," Proceedings of the Seventeenth Midyear Topical Symposium of the Health Physics Society, Computer Applications in Health Physics, Richland, Washington, February 5-9, 1984. 

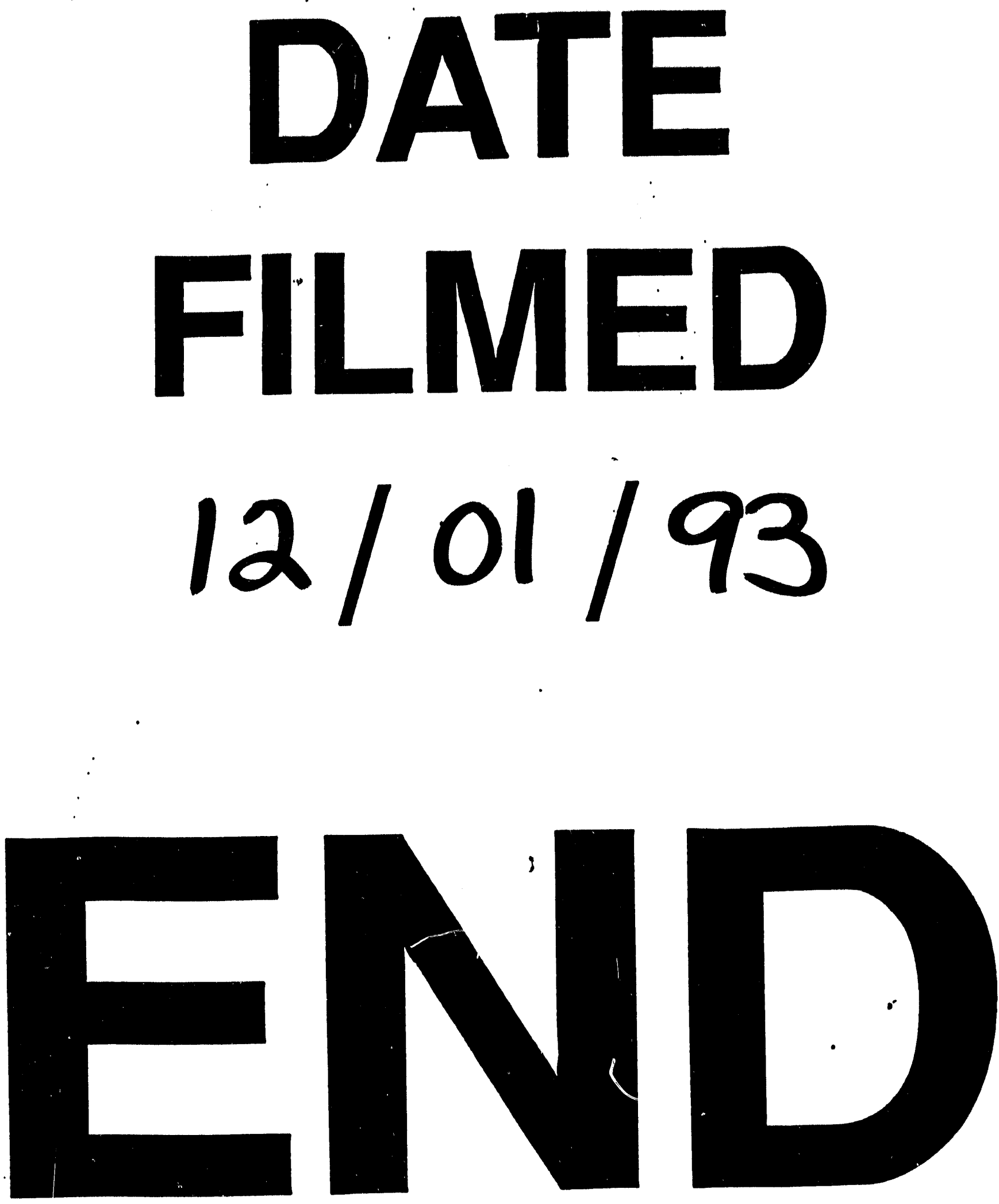